\title{
Novel electrocardiographic indices of arrhythmogenesis and blood lead level
}

\section{Dear Editor,}

We have read with interest the publication by Karakulak et al. that discusses electrocardiographic findings in workers with lead exposure (Karakulak, Yilmaz, Tutkun, Gunduzoz, \& Ercan Onay, 2016). The associations between blood lead levels and the duration of QT and PR intervals have been previously examined (Chen et al., 2013). Current study expands the effects of blood concentrations of this heavy metal on to newly introduced markers of arrhythmogenesis. It is implied that the interval from the peak to the end of $\mathrm{T}$ wave (Tp-e) is indicative of transmural dispersion of repolarization. In healthy individuals, Tp-e/QT ratio is $0.21 \pm 0.03$, and higher value is regarded as novel index of ventricular dysrhythmia (Gupta et al., 2008). Similarly, dispersion of $P$ wave (PWD) has been predictive of atrial arrhythmias (Nussinovitch, 2012). Therefore, the correlation that may exist between the newly described indices and lead levels is worthy of examining. Blood lead levels are expectedly higher in the environmentally exposed group compared to the control group, however, the overall differences in electrocardiographic findings are not quite impressive. Despite higher values of the P wave and QT dispersion in the exposed group, they fall within the normal range of PWD $(33.5 \pm 9.7 \mathrm{~ms})$ and those of QTD $(10-71 \mathrm{~ms})$ in both groups (Malik \& Batchvarov, 2000; Nussinovitch, 2012). Accordingly both groups are categorized as normal with regard to PWD, QTD, QT interval, and Tp-e measurements. Whether the statistically differences between two values that both are within normal range will increase the probability of dysrhythmia remains highly speculative. Authors state that in multivariate logistic regression model, none of the laboratory findings including blood lead level is identified as an independent predictor of electrocardiographic findings. Particularly, further attempts to correlate the blood lead level with various electrocardiographic indices in univariate analysis yield only a weak correlation for some of the indices and no correlation whatsoever for the rest. Blood lead levels $>10 \mu \mathrm{g} / \mathrm{dl}$ is generally regarded abnormal and associates with cardiovascular, as well as all-cause mortality (Lustberg \& Silbergeld, 2002). Interestingly, in this study reported blood lead levels are unusually low in the control group $(0.3 \mu \mathrm{g} / \mathrm{dl})$, and probably not a true representative of population. Studies from the same geographical region on occupationally unexposed population have yielded much higher levels between 3.1 to as high as $8.6 \mu \mathrm{g} / \mathrm{dl}$ (Kirel, Aksit, \& Bulut, 2005; Pala, Turkkan, Gucer, Osman, \& Aytekin, 2009; Vural \& Gulvendik, 1988). Additionally, average blood lead level in the United States among adults has been reported $1.2 \mu \mathrm{g} / \mathrm{dl}$ during
2009-2010. On the other hand, blood levels as low as $4.9 \mu \mathrm{g} / \mathrm{dl}$ are reported in patients with lead exposure, which make this group highly heterogeneous. It would be interesting if the authors perform additional comparison between individuals with blood lead level above $10 \mu \mathrm{g} / \mathrm{dl}$ and those with levels below $10 \mu \mathrm{g} / \mathrm{dl}$ considering abnormal blood lead level as binary variable. With the currently provided information, the study's conclusion of "higher risk of atrial and ventricular arrhythmias for lead-exposed workers" seems too strong and is not well supported.

\section{FUNDING RESOURCE}

None.

\section{CONFLICTS OF INTEREST}

The authors declare that they have no conflicts of interest.

Leili Pourafkari M.D., F.A.C.C. ${ }^{1,2}$ Arezou Tajili M.D. ${ }^{3}$ Nader D. Nader M.D., PhD., F.A.C.C. ${ }^{2}$

${ }^{1}$ Department of Cardiology, Tabriz University of Medical Science, Tabriz, Iran

${ }^{2}$ Department of Anesthesiology, University at Buffalo, Buffalo, NY, USA ${ }^{3}$ Cardiovascular Research Center, Tabriz University of Medical Science, Tabriz, Iran

Correspondence Nader D. Nader, M.D., PhD., F.A.C.C., Department of Anesthesiology, University at Buffalo, Buffalo, NY, USA. Email:nnader@buffalo.edu

\section{REFERENCES}

Chen, C. C., Yen, H. W., Lo, Y. H., Chu, Y. H., Chiu, Y. W., \& Chuang, H. Y. (2013). The association of prolonged QT interval on electrocardiography and chronic lead exposure. Journal of Occupational and Environmental Medicine, 55, 614-619.

Gupta, P., Patel, C., Patel, H., Narayanaswamy, S., Malhotra, B., Green, J. T., \& Yan, G. X. (2008). T(p-e)/QT ratio as an index of arrhythmogenesis. Journal of Electrocardiology, 41, 567-574.

Karakulak, U. N., Yilmaz, O. H., Tutkun, E., Gunduzoz, M., \& Ercan Onay, E. (2016). Comprehensive electrocardiographic analysis of lead exposed workers: An arrhythmic risk assessment study. Annals of Noninvasive Electrocardiology. doi:10.1111/anec.12376

Kirel, B., Aksit, M. A., \& Bulut, H. (2005). Blood lead levels of maternal-cord pairs, children and adults who live in a central urban area in Turkey. The Turkish Journal of Pediatrics, 47, 125-131.

Lustberg, M., \& Silbergeld, E. (2002). Blood lead levels and mortality. Archives of Internal Medicine, 162, 2443-2449. 
Malik, M., \& Batchvarov, V. N. (2000). Measurement, interpretation and clinical potential of QT dispersion. Journal of the American College of Cardiology, 36, 1749-1766.

Nussinovitch, U. (2012). Meta-analysis of p-wave dispersion values in healthy individuals: The influence of clinical characteristics. Annals of Noninvasive Electrocardiology, 17, 28-35.
Pala, K., Turkkan, A., Gucer, S., Osman, E., \& Aytekin, H. (2009). Occupational lead exposure: Blood lead levels of apprentices in Bursa, Turkey. Industrial Health, 47, 97-102.

Vural, N., \& Gulvendik, G. (1988). Blood lead level distribution by age group in inhabitants of Ankara. Biological Trace Element Research, 18, 85-93. 